\title{
Exploration on the Training of Advertising Teaching Based on the New Period
}

\author{
Jing Wang \\ Xi'an university school of humanities, 710065
}

\author{
Keywords: New Period; Advertising Teaching; Training; Exploration
}

\begin{abstract}
In recent years, under the situation of large-scale enrollment in colleges and universities in China, the field of advertising education in our country has paid great attention to the education of applied subjects. Based on the characteristics of this new application period, the practical teaching content of advertising teaching is becoming more and more important for colleges and universities. How to carry out advertising teaching training attempt in the application of undergraduate colleges and universities scientifically and reasonably, especially in the practice of training base conditions already available, which is the focus of this paper. The paper hopes to explore a series of advertising teaching and training activities methods that have good practice, operation and quality assessment based on the school and the enterprise.
\end{abstract}

\section{Introduction}

In the new period, the market economy is facing new opportunities for development due to the continuous development of Chinese network and new media industry. Advertising design and advertising has an increasingly obvious role in the sales and daily production and life. Whether it is for the purpose of profit or for the purpose of public culture, both of them need a lot of high-tech advertising talent to complete. Chinese education sector pointed out that the development of vocational education is Chinese current important and urgent work in the education guidance document. And promote the practice of advertising teaching development and build vocational education advertising training base have a very important significance for vocational education and economic development. Colleges and universities provide theoretical basis and then combine with the enterprise to cultivate students practical teaching ability and establish training base, which can explore advertising teaching practice problems of various aspects of the implementation of the higher vocational schools.

\section{The Background of Combination of Theory and Practice in Teaching}

The Background of Training Spirit. Chinese traditional education has long focused on the traditional classics, literature research and theoretical study. However, after the reform and opening up, a large number of new disciplines branch teaching concept appear by the impact of foreign Western educational philosophy. With the rapid economic growth and the needs of the market economy, the demand for complex talents and sophisticated professional talents is abundant, which makes our education and research departments actively promote the higher vocational teaching theory combine with the practice and promote the spirit of artisans and the spirit of the use in the specific educational practice. At the same time, it become one of the key needs of the current development of Chinese education system. On this basis, Chinese education sector put forward a lot of guidance and very clearly pointed out that Chinese applied undergraduate professional teaching and higher vocational education teaching must attach great importance to the research and exploration of teaching and training new problems.

From the advertising point of view, the characteristic of advertising is to be able to cater to people for a particular demand, which spreads through a certain media to public widely. Broad advertising include economic and non - economic. However, $70 \%$ or more is for the purpose of profit and the achievement of this purpose will directly affect the rise and fall of the enterprise and the economic interests of enterprises. The purpose of advertising is very obvious. Therefore, it is very helpful for the growth of advertising talent through training to understand the public feedback 
on advertising and to understand the timeliness of advertising effectiveness in the new period. At the same time, it is very necessary for teaching and it is the bearing and extension of teaching theory.

The Core Idea of Advertising. Advertising professional is generally opened by the University, aiming to cultivate professional talents with professional advertising theory and skills, broad advertising culture and scientific knowledge. Advertising professionals cultivated by colleges and universities can have a good chance in the news media advertising department, advertising companies and market research and information consulting industry, especially in Chinese important enterprises and institutions. With the rapid development of the economy, if companies want to have a good position in the market or can effectively deal with crisis public relations, they will need a large number of specialized advertising business and management personnel, advertising planning and creative talent, advertising design and production talent, marketing and planning talent, market research and analysis of talent. This type of talent is known as the advertising expertise of senior professionals, generally cultivated by vocational colleges and applied undergraduate.

The core idea of advertising professional is committed to build a groundbreaking advertising business. Advertising classification is relatively more detailed and academic methods is carried out to explore. The core idea of advertising which can make independent teaching and research advertising history, theory, strategy, production and management is to study market economy, consumer psychology and aesthetics to enhance people's awareness of consumption and result in social psychological resonance. Advertising knowledge and other knowledge is synergy and it is a publicity based on the proficient and understanding the psychology of consumers, which have a very deep contact with journalism, marketing, business management, business psychology and other disciplines.

\section{The Development of Integrated Teaching Practice Mode in Modern Education}

The Development of Simulation Training in Advertising Course. In our country, there is no simulated training for early advertising courses. The early advertising tutorial did not exist as a very important undergraduate teaching content, while the main practice content was generally reflected in the internship after graduation when the advertising became a specialized branch. A large number of advertising talents begin to work in the advertising company through simple training and semi-self-learning process, so the advertising talents more emphasis on simple design talent.

With the rapid development of market economy, the research and analysis requirements are getting higher and higher for advanced advertising planning market trends. This requires a variety of talent in the field of advertising, especially the talent who can stand on the management level to carry out the entire advertising and marketing planning. The demand is very large in the large-scale enterprises and in the process of analysis of the entire industry.

In recent years, with the voice of education reform in higher vocational colleges in China continue to sound, the researchers establish a set of research system based on advertising training and gradually establish the advertising professional teaching and training integration mode. Enterprises are also getting benefits in the process of cooperation with colleges and universities. It improve the rationality of the advertising curriculum system from the advertising training course case selection and configuration to achieve the rationalization and institutionalization of the teaching model, making advertising professional teaching and training integration model become a necessity.

The Development and Evolution of the Cooperation Training of School and Enterprise in Advertising Course. The cooperation between advertising company and the school is very popular in this situation. From the early simple simulation environment and a single link of business operation to the latter part of the project as the main body, with professional training courses and classroom combination, modern advertising courses training has formed an integrated and one-stop training opportunities. Training and curriculum teaching should be integrated with each other.

In the process of continuous development and evolution, advertising training program that 
schools cooperate with enterprises has gone through the initial stage. At present, Chinese vocational colleges in order to cultivate students' innovative spirit and improve students' practical ability, two companies begin to cooperate with each other in the background of profound advertising culture quality education reform. A series of effective educational practice reforms should be carried out from hardware environment, software environment, human environment and other aspects of modern educational technology environment. In particular, it is worthy of praise that compilation work for vocational colleges advertising education has achieved good results.

The Narrow Concept of Integrative Teaching Practice in Advertising Specialty. The narrow concept of integrative teaching practice in advertising specialty is aimed at the general concept of advertising. Advertisements in the narrow sense point to advertising content that is tied to the purpose of economic profitability. From the advertising professional teaching practice in the narrow sense, it refers to advertising discipline teaching content for the development needs of company. Narrow advertising teaching training pays more attention to the enterprise's human resources and to grasp the rules of the market, hoping advertising professionals to adapt more quickly the needs of business and social development. Therefore, this practical training course is generally highly operational. Besides, many schools and enterprises will also let students work and create directly on specific advertising projects.

The Relationship between Advertising Course Structure and Teaching Content and Teaching Practice. Only a reasonable advertising course structure and teaching content can promote education training. The teaching theory that education training and social development can not be consistent is not able to adapt to the development needs of advertising education training. At present in the process of advertising education, institutions of higher learning often want to be creative in the process of advertising teaching, so it is very important to reform the syllabus and teaching curriculum structural of advertising copy. In the new media era, understand the basic composition of advertising professionals and explore the basis of advertising professionals and curriculum teaching innovation deeply. As the advertising profession requires students to have a very basic advertising design capabilities, so it is not good enough for students only to have theoretical knowledge and no hands-on ability. It is the original intention and focus to reform the basic curriculum of advertising in colleges and universities that lays a solid foundation for students to adapt to the future society, which is to enhance the professional course of advertising from the professional level and comprehensive quality of advertising students. Basic courses and hands-on courses have now been widely concerned by the university. Meanwhile, the extension of basic courses also become the focus of education for teachers.

The Realization Path of Practical Teaching of Advertising Teaching in the New Period

The Combination of Advertising Theory Teaching and Skill Teaching. The rapid development of science and technology makes the division of disciplines more meticulous, which makes the disciplines continuous impact each other. Advertising theory teaching and skills teaching are currently two major branches of design professional teaching. The two branches are equally important and together constitute the advertising teaching that is a important teaching system. Advertising professional teaching requires students to have the basis of the design performance capabilities. Only master the mainstream of advertising teaching theory and design techniques and master the basic courses, curriculum branches and advertising genre evolution, students can summarize the most basic and natural objects into what they want to express. Besides, students need to design and create a new advertising image through generalizing and restructuring highly the intention of customers want to express on the basis of the usage of skilled hand-painted or software.

Advertising designers not only require the ability to master the aesthetic principles, but also should be able to grasp the most basic advertising genre and theory. They can turn what they thought into reality through active and positive innovation. In China, a lot of advertising students did not undergo the relevant art training before higher education, so the relative basis of painting and abstract thinking ability is very weak. The majority of colleges and universities hope to strengthen the technical level of advertising students from the perspective of practical training, forging their design thinking ability and mobilizing their autonomy and innovation in practice. 
Set up Courses Combined with the Development Requirement in the New Period. As the advertising performance techniques and advertising media develops so fast, which requires advertising professional college teachers should advance with the times in this process, which requires teachers should understand the latest advertising genre, advertising practices, advertising forms and advertising content changes. Besides, advertising information delivery appeal is always closely related with the needs of advertising employers. Therefore, the curriculum in higher vocational colleges and other institutions should be adjusted all times to break the traditional three-stage teaching content. The advertising education curriculum in the new period should be as much as possible to connect different parts of the advertising curriculum structure and adjust the focus of advertising professional courses. With the development of modern technology curriculum education, skills teaching and basic teaching should connect with practical training and specific teaching cases. To promote the group exploration and the project research and development system in the teaching. Meanwhile arrange the design curriculum and theoretical courses scientifically and reasonably, as well as the proportion of teaching time, so that the whole course can be improved.

The curriculum of colleges and universities should be combined with theory and practice, combining practice with experiment, combining basic and professional, combining single subject and multi-discipline to make the average distribution of content and time, especially in technology integration strategy. As information technology has two sides, advertising design requires the support of software and information technology, so the proportion setting of the curriculum should focus on the allocation of time.

The Completeness and Coherence of Advertising Training Conforms to the Curriculum. The process of this form of education may be staged due to the difference between the training course and the theoretical course. Each stage of the training course should be guided by theoretical courses. However, in the course of training should not only take into account the integrity of teaching, but also should take into account the convergence of theoretical courses and teaching. The coherence of advertising training courses should be consistent with the entire curriculum, and teachers should grasp completely the development needs of enterprises at this stage. Simply put, although advertising teaching course can get some profit and reward in a certain degree, but its fundamental purpose is to assist the learning of advertising professional theory as a typical teaching case with the entire advertising teaching curriculum architecture.

Training Professional Teachers Who Understand the Advertising Market Conditions and Training Environment. At present, young teachers have a very obvious advantage in the training of advertising teaching teachers, especially for the mastering of information technology and software technology. Cultivating teachers with practical experience and practical advertising operation and design experience is very welcome to higher vocational colleges. Schools should pay more attention to teachers who have specific practice and practical experience when recruit. For example, improve welfare and relax the recruitment age to attract compound talents to join and enhance the effectiveness level of the entire faculty.

Establish Training Cooperation Center of Schools and Enterprises. School-enterprise cooperation center is the base of new century advertising teaching and training. Application-oriented talent must have a platform for training and this platform is based on a reasonable curriculum. If want to make students more proficient in the development of the entire advertising industry and business processes, the establishment of a business integration with the enterprise training center is very necessary. In recent years, a wide range of commercial consulting, exhibition public relations, online sales, visual arts and other advertising industries need schools and businesses to create a reasonable training environment.

\section{Conclusion}

Advertising professional adopt professional teaching and training integration mode to break the traditional imitation and classroom teaching methods and actively face the teaching reform and adjustment. Besides, it also integrate the entire advertising teaching curriculum resources with the 
rapid development of information technology. The advertising teaching practice education in new period need to integrate the entire advertising teaching comprehensive ability from the hardware, software and human environment and other aspects, which requires vocational colleges and colleges and universities must use professional knowledge to create a suitable advertising teaching environment and have good teachers who can improve the learning ability of advertising professional students.

\section{Reference}

[1] Y.H. Li. Research on the Innovative Ways of Advertising Design Teaching in Art Design Specialty in Colleges and Universities [J]. Fine Arts Education Research, 2017, (14): $118+120$.

[2] J.W. Yang and X.Q. Su. Research on the Teaching of "New Energy Vehicle Technology" in Secondary Vocational Schools [J]. Vehicle Maintenance, 2017, (07): 16-18.

[3] C.M. Fu. Research on "Advertising Photography and Camera" Teaching Mode Reform [J]. Industry and Technology Forum, 2017, 16 (11): 124-125.

[4] X.B. Zhang. Teaching Strategies and Evaluation Criteria for Group Learning in Advertising Teaching [J]. Modern Vocational Education, 2017, (15): 78.

[5] Y. Liu. Research on the Three-dimensional Teaching Mode of Advertising English [J]. Jilin Education, 2017, (17): 1.

[6] W. Zhong. Research on the Teaching Reform of Advertising Design in Colleges and Universities under the New Situation [J]. College Entrance Examination, 2017, (09): 14.

[7] Y.L. Pan. Research on the Teaching Reform of Art Design in Higher Vocational Education [J]. Literature Education (2), 2017, (03): 184.

[8] J. Feng and J. Pan. New Path of "Internet + Education": Practice Teaching Mode of Advertising Specialty Based on Crowdsourcing Platform [J]. Southwest Communication, 2017, (03): 103-104.

[9] L. Lu. Analysis on the Innovative Development of Advertising Teaching in the New Media Environment [J]. Chinese Inspirational, 2017, (05): 126.

[10]F. Gao. Practice and Exploration of "Advertising Creative" Excellent Course Based on the Cultivation of Innovation Ability [J]. The United States and the Times (1), 2017, (03): 120-123.

[11] Y. Wang. Research on the Innovation of Simulated Situational Advertisement Planning and Creative Practice Teaching Mode [J]. Journal of Higher Education, 2017, (05): 33-34.

[12] M.Y. Hu. Innovative Practice of Mixed Teaching Mode of "Visual, Creative, Marketing, Communication - Understanding Advertising" Course Based on Network Information Platform [J]. Industry and Information Education, 2017, (01): 33-36. 